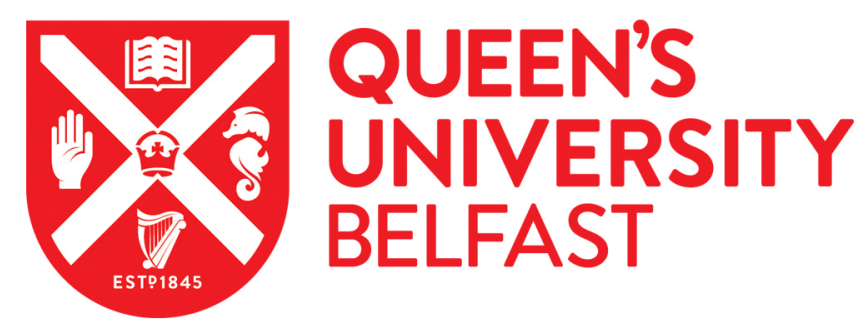

\title{
Electrosprayed cysteine-functionalized degradable amphiphilic block copolymer microparticles for low pH-triggered drug delivery
}

Finnegan, M., Mallon, G., Leach, A., \& Themistou, E. (2019). Electrosprayed cysteine-functionalized degradable amphiphilic block copolymer microparticles for low pH-triggered drug delivery. Polymer Chemistry, 10, 58145820. https://doi.org/10.1039/c9py01221d

Published in:

Polymer Chemistry

Document Version:

Peer reviewed version

Queen's University Belfast - Research Portal:

Link to publication record in Queen's University Belfast Research Portal

Publisher rights

(c) 2019 The Royal Society of Chemistry.

This work is made available online in accordance with the publisher's policies. Please refer to any applicable terms of use of the publisher.

\section{General rights}

Copyright for the publications made accessible via the Queen's University Belfast Research Portal is retained by the author(s) and / or other copyright owners and it is a condition of accessing these publications that users recognise and abide by the legal requirements associated with these rights.

Take down policy

The Research Portal is Queen's institutional repository that provides access to Queen's research output. Every effort has been made to ensure that content in the Research Portal does not infringe any person's rights, or applicable UK laws. If you discover content in the Research Portal that you believe breaches copyright or violates any law, please contact openaccess@qub.ac.uk. 


\title{
Electrosprayed cysteine-functionalized degradable amphiphilic block copolymer microparticles for low pH-triggered drug delivery
}

Received 00th January 20xx, Accepted 00th January 20xx DOI: $10.1039 / x 0 x \times 00000 x$

\begin{abstract}
Marie Finnegan, ${ }^{a}$ Gerard Mallon, ${ }^{a}$ Adam Leach ${ }^{b}$ and Efrosyni Themistou ${ }^{* a}$
Thiol-functionalized polymeric microparticles have attracted interest as mucoadhesive drug delivery formulations. However, new approaches are needed to optimize the preparation of these systems for patient use. Here, $N$-hydroxysuccinimide (NHS)-functionalized degradable amphiphilic diblock copolymer microparticles are prepared via electrospraying and subsequently functionalized with thiols. A poly(L-lactide)-b-poly(2-(methacryloyloxy)ethyl phosphorylcholine)-st(methacrylic acid NHS ester)) (PLA-b-P(MPC-st-NHSMA)) diblock copolymer was synthesized by sequential ring opening polymerization and reversible addition-fragmentation chain transfer polymerization. One-step microparticle preparation and Rhodamine B encapsulation was performed by electrospraying. Cysteine attachment to the microparticle surface via succinimide chemistry resulted in their functionalization with thiol groups. These reacted with Fluorescein isothiocyanate (FITC) to provide a fluorescent tag, proving the thiol reactivity. High controlled release of the dye was observed at low $\mathrm{pH}$ over a period of 89 days. These thiol-functionalized degradable microparticles are expected to have enhanced mucoadhesive properties with high potential for use as next-generation formulations for low $\mathrm{pH}$, such as gastric, drug delivery.
\end{abstract}

\section{Introduction}

Synthetic polymeric microparticles have attracted the interest of many researchers as carriers for oral drug and protein delivery due to the ability of polymer chemistry to easily fine tune their properties. ${ }^{1-3}$ However, there are still some challenges associated with oral delivery including a narrow absorption window in the upper gastrointestinal tract. Therefore, prolonging the time period the drug spends at the absorption site can be beneficial. Mucoadhesion has been widely promoted as a method of site specific gastric drug delivery, ${ }^{4-6}$ improving bioavailability and residence time of the encapsulated drug. ${ }^{7}$

The aliphatic polyesters poly(lactic-co-glycolic acid) (PLGA) ${ }^{8}$ and poly(lactide) (PLA) ${ }^{9}$ are commonly used in the preparation of polymeric microparticles for drug delivery due to their biocompatibility and biodegradability ${ }^{10}$. However, PLA microparticles are susceptible to a high initial burst release of encapsulated cargo. $^{11}$ In order to achieve high drug encapsulation efficiency and loading, and a controlled drug release rate, PLA can be coated, blended or copolymerized with a hydrophilic polymer/monomer. ${ }^{12}$ Also, incorporation of functional groups in PLA structure can be challenging since these are often not tolerated in the ring opening polymerization $(\mathrm{ROP})^{13,14}$ methodology that is used for its synthesis. By using a

${ }^{a}$ School of Chemistry and Chemical Engineering, Queen's University Belfast, David Keir Building, Belfast BT9 5AG, UK. E-mail: e.themistou@qub.ac.uk

${ }^{b}$ Centre for Cancer Research \& Cell Biology, Queen's University Belfast, Belfast BT9 $7 A E, U K$

+Electronic Supplementary Information (ESI) available.

See DOI: $10.1039 / x 0 x x 00000 x$ more versatile polymerization technique, such as reversible addition-fragmentation chain transfer (RAFT) polymerization, ${ }^{15,16}$ in combination with ROP, ${ }^{17-27}$ for the synthesis of the hydrophilic block of a PLA-based amphiphilic block copolymer, different functional groups can be incorporated in the polymer. These functional groups can give interesting properties to the amphiphilic block copolymer. For example, the presence of reactive thiols ${ }^{22,28}$ can endow the polymer with mucoadhesive properties. ${ }^{29,30}$ Combining ROP and RAFT polymerization has been used before for synthesizing biodegradable polymers for the formation of polymeric particles. ${ }^{17}$ However, combining ROP and RAFT polymerization to copolymerize dissimilar monomers can be difficult. Several researchers have overcome issues in synthesizing block copolymers by combining these two polymerization techniques in one pot by using a dual reagent that can initiate both techniques. ${ }^{19-27}$ These polymerizations can take place either as a single reaction, where both polymerizations are taking place simultaneously, ${ }^{19,22-24,27}$ or as sequential reactions, ${ }^{20-22,25,26}$ in cases where the polymerizations require different conditions.

Many methods of microparticle production have been used over the last number of decades including emulsion-solvent diffusion, $^{2}$ solvent evaporation, ${ }^{31}$ phase separation, ${ }^{32}$ spray drying ${ }^{33}$ and electrospraying. ${ }^{34}$ Electrospraying has emerged as a cost-effective and versatile technique for microparticle preparation. ${ }^{35}$ The process involves atomisation of a polymer solution via the application of an electric field in order to produce polymeric microparticles. ${ }^{36}$

Herein, we report the one-pot two-step synthesis of a NHSfunctionalized poly(L-lactide)- $b$-poly(2-(methacryloyloxy)ethyl phosphorylcholine)-st-(methacrylic acid $N$-hydroxysuccinimide ester)) (PLA-b-P(MPC-st-NHSMA)) amphiphilic diblock 


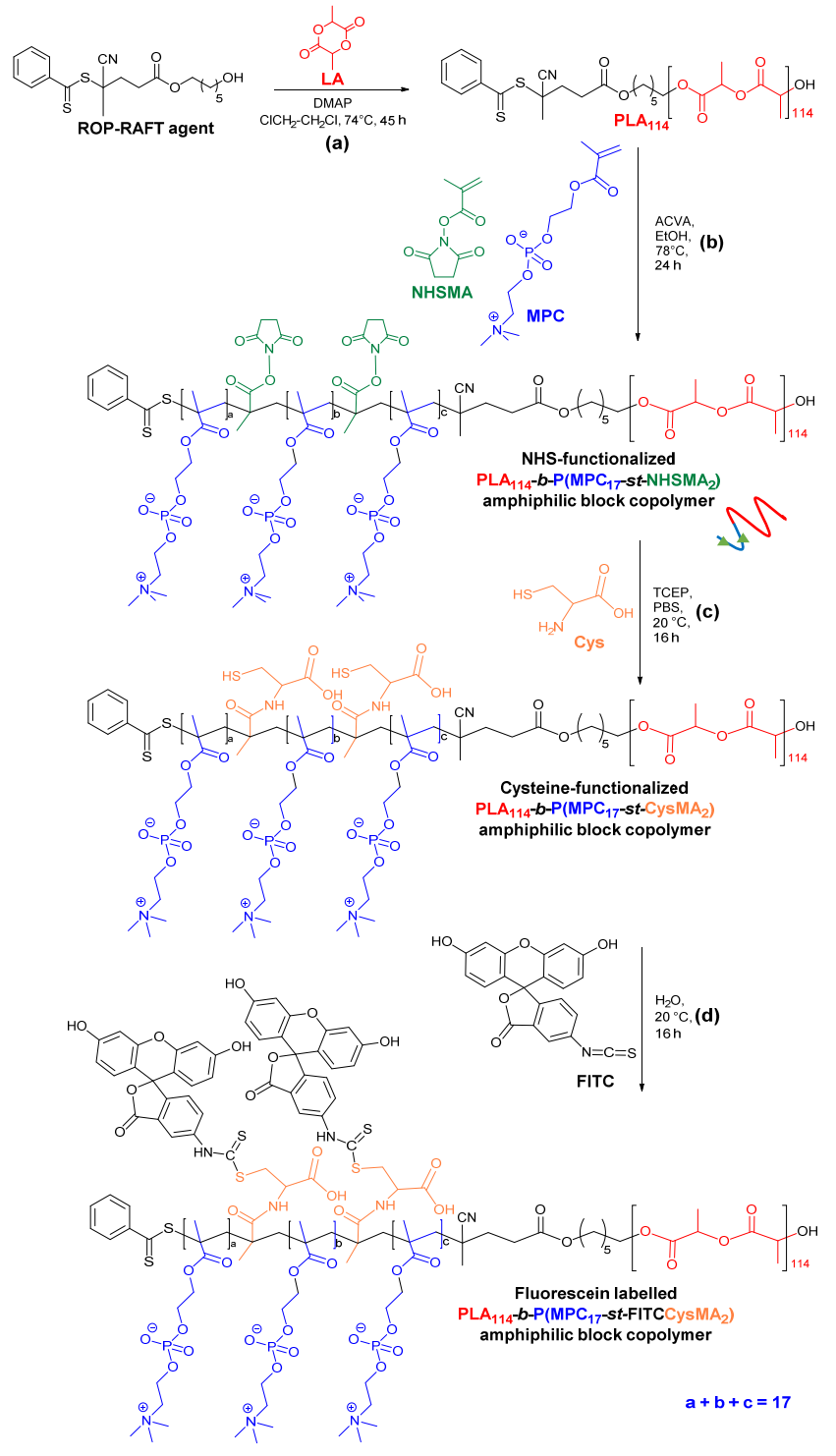

Scheme 1 Preparation of cysteine- and FITC- functionalized amphiphilic block copolymers. NHS-functionalized degradable $\mathrm{PLA}_{114}-b-\mathrm{P}\left(\mathrm{MPC}_{17}-\mathrm{st}-\mathrm{NHSMA}_{2}\right)$ amphiphilic diblock copolymer synthesis by a two-step procedure: (a) ROP of LA and (b) RAFT statistical copolymerization of MPC and NHSMA using a dual ROPRAFT reagent; (c) cysteine functionalization resulting in the formation of thiolfunctionalized degradable $\mathrm{PLA}_{114}-b$ - $\mathrm{P}\left(\mathrm{MPC}_{17}\right.$-st-CysMA $\left.\mathrm{M}_{2}\right)$ amphiphilic diblock copolymer; (d) FITC functionalization and preparation of $\mathrm{PLA}_{114}-b$-P $\left(\mathrm{MPC}_{17}\right.$-stFITCCys $\mathrm{MA}_{2}$ ) amphiphilic diblock copolymer with a fluorescent tag.

copolymer by sequential ROP (Scheme 1a) and RAFT polymerization (Scheme $1 \mathrm{~b}$ ). A two-step reaction is used for the preparation of this polymer due to the insolubility of PMPC in solvents that are appropriate for ROP. A chloroform/methanol $\left(\mathrm{CHCl}_{3} / \mathrm{CH}_{3} \mathrm{OH}\right.$ ) solution of this polymer (Scheme $2 \mathrm{a}$ ) was used in the production of biocompatible biodegradable microparticles via electrospraying (Scheme $2 b$ ). The amphiphilic diblock copolymer was designed to have a range of functional properties. The biodegradability of $\mathrm{PLA}^{37}$ provides the microparticles with a controlled release mechanism for encapsulated moieties at low pH. PMPC is a highly hydrophilic polymer that exhibits a high level of bio/hemo-compatibility. ${ }^{38}$ The $\mathrm{N}$-hydroxysuccinimide group of the NHSMA monomer allows for subsequent cysteine attachment to the hydrophilic

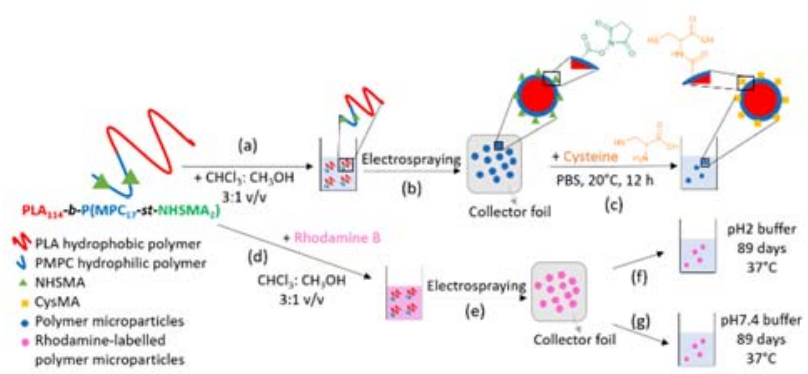

Scheme 2 Schematic representation of (a) the formation of $\mathrm{PLA}_{114}-b-\mathrm{P}\left(\mathrm{MPC}_{17^{-}}\right.$ st-NHSMA ${ }_{2}$ ) amphiphilic diblock copolymer microparticles (b) via electrospraying and the subsequent (c) attachment of cysteine on their surface to provide thiol-functionalized microparticles; (d) Encapsulation of Rhodamine $\mathrm{B}$ in $\mathrm{PLA}_{114}-b-\mathrm{P}\left(\mathrm{MPC}_{17}-\right.$ st-NHSMA$\left.{ }_{2}\right)$ microparticles by (e) electrospraying; dye release at $37^{\circ} \mathrm{C}$ in PBS buffer at (f) pH 2 and (g) pH 7.4.

PMPC polymer block through a reaction with its primary amine group to form a stable amide bond ${ }^{39}$ (Scheme 1c), decorating the resulting microparticle surface with thiol functional groups (Scheme 2a-c). These free thiols can then react with the isothiocyanate group ${ }^{40}$ of Fluorescein isothiocyanate (FITC) to give a fluorescent tag (Scheme $1 \mathrm{~d}$ ). Rhodamine $\mathrm{B}$, used as a model drug molecule surrogate, was mixed with the polymer (Scheme 2d) and was encapsulated in the microparticle structure during electrospraying (Scheme 2e). Its release was monitored both in low $(\mathrm{pH} 2)$ and physiological $(\mathrm{pH}$ 7.4) $\mathrm{pH}$ values (Scheme $2 \mathrm{f}$ and $2 \mathrm{~g}$, respectively). These thiolfunctionalized microparticles are useful for encapsulation of drugs and potential drug delivery applications in the stomach due to their biocompatibility, biodegradability, mucoadhesive properties and controlled release profile in low $\mathrm{pH}$.

\section{Experimental}

\section{Materials}

All chemicals were purchased from Sigma-Aldrich and were above $97 \%$ purity unless stated otherwise. Fluorescein isothiocyanate (FITC) ( $\geq 90 \%)$ was also purchased from SigmaAldrich. Spectra/Por 6 dialysis tubing with molecular weight (MW) cut-off (MWCO) of 1 kD was purchased from Spectrum Labs (USA). Nunc ${ }^{\mathrm{TM}}$ MicroWell ${ }^{\mathrm{TM}}$ 96-Well Optical-Bottom plates with polymer base were purchased from ThermoFisher Scientific. L-lactide (LA) was recrystallized 4-5 times from ethyl acetate prior to use. The ROP-RAFT dual agent was synthesized in-house using the procedure reported by Themistou et al. ${ }^{22}$

\section{Synthesis of $\mathrm{PLA}_{114}-b-\mathrm{P}\left(\mathrm{MPC}_{17}\right.$-st-NHSMA $)$ amphiphilic diblock copolymer}

LA (3.65 g, $25.3 \mathrm{mmol})$, ROP-RAFT agent (0.08 g, $0.211 \mathrm{mmol})$, 4-dimethylaminopyridine (DMAP) $(0.206 \mathrm{~g}, 1.69 \mathrm{mmol})$ and $3.93 \mathrm{~mL}$ of 1,2-dichloroethane were added to a $100 \mathrm{~mL}$ round bottom flask equipped with a magnetic stirring bar and rubber septum. The mixture was purged with nitrogen gas for $20 \mathrm{~min}$ and then it was placed in an oil bath set at $74^{\circ} \mathrm{C}$. The reaction was left to proceed for $45 \mathrm{~h}$, then it was cooled to room temperature and a sample was taken for proton nuclear 
magnetic resonance $\left({ }^{1} \mathrm{H} \quad \mathrm{NMR}\right)$ analysis in deuterated chloroform $\left(\mathrm{CDCl}_{3}\right)$. 2-Methacryloyloxythyl phosphorylcholine (MPC, $1.12 \mathrm{~g}, 3.79 \mathrm{mmol}$ ), 4,4'-azobis(4-cyanovaleric acid) (ACVA, $11.8 \mathrm{mg}, 0.0422 \mathrm{mmol}$ ), methacrylic acid $\mathrm{N}$ hydroxysuccinimide ester (NHSMA, $0.077 \mathrm{~g}, 0.422 \mathrm{mmol}$ ) and $20.56 \mathrm{~mL}$ of ethanol were added to the reaction mixture. The resulting mixture was purged with nitrogen gas for $20 \mathrm{~min}$. The flask was left to stir in an oil bath at $78^{\circ} \mathrm{C}$ for $24 \mathrm{~h}$. The reaction was then cooled to room temperature and a sample was taken for ${ }^{1} \mathrm{H} \quad \mathrm{NMR} \quad\left(\mathrm{CDCl}_{3}\right)$ spectroscopy and size exclusion chromatography (SEC) using a chloroform $\left(\mathrm{CHCl}_{3}\right)$ / methanol $\left(\mathrm{CH}_{3} \mathrm{OH}\right) 3 / 1 \mathrm{v} / \mathrm{v}$ solvent mixture as eluent. Dialysis was performed against acetone (MWCO 1 kD, 4 times), followed by dialysis against methanol (MWCO 1 kD, 4 times). The final PLA$b$-P(MPC-st-NHSMA) amphiphilic block copolymer was dried under vacuum and characterised by ${ }^{1} \mathrm{H} \quad \mathrm{NMR}\left(\mathrm{CDCl}_{3} /\right.$ deuterated methanol $\left.\left(\mathrm{CD}_{3} \mathrm{OD}\right) 3 / 1 \mathrm{v} / \mathrm{v}\right)$ and $\mathrm{SEC}\left(\mathrm{CHCl}_{3} / \mathrm{CH}_{3} \mathrm{OH}\right.$ $3 / 1 \mathrm{v} / \mathrm{v})$.

\section{Polymer characterization}

All ${ }^{1} \mathrm{H}$ NMR spectra were recorded using a Bruker Avance 400 $\mathrm{MHz}$ or $600 \mathrm{MHz}$ spectrometer. The molecular weight distribution of the PLA- $b$-P(MPC-st-NHSMA) amphiphilic diblock copolymer was assessed by SEC using an Agilent Technologies 1260 Infinity system with a refractive index (RI) detector. The system comprised of a guard column and two Agilent PL gel 5 $\mu \mathrm{m}$ MIXED-C columns. The columns were connected in series and were operating at $35{ }^{\circ} \mathrm{C}$, while the $\mathrm{RI}$ detector was maintained at $40^{\circ} \mathrm{C} . \mathrm{A} \mathrm{CHCl}_{3} / \mathrm{CH}_{3} \mathrm{OH} 3 / 1 \mathrm{v} / \mathrm{v}$ mixture with $2 \mathrm{mM}$ lithium bromide $(\mathrm{LiBr})$ was used as the eluent at a flow rate of

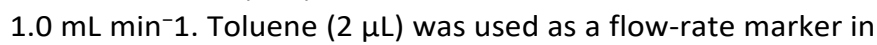
each sample. The calibration was performed using a series of ten near-monodisperse poly(methyl methacrylate) (PMMA) standards purchased from Agilent with MWs of 1010, 1950, 6850, 13 900, 31 110, 68 750, 137 800, 320 000, 569000 and 1 $048000 \mathrm{~g} \mathrm{~mol}^{-1}$. Cirrus ${ }^{\mathrm{TM}}$ software from Agilent was used for the analysis of the SEC chromatograms.

\section{Electrospraying of $\mathrm{PLA}_{114}-b-\mathrm{P}\left(\mathrm{MPC}_{17}\right.$-st-NHSMA $)$ amphiphilic diblock copolymer solution to produce microparticles}

A $339 \mathrm{mg} \mathrm{mL} \mathrm{mLA}_{114}-b-\mathrm{P}\left(\mathrm{MPC}_{17}-\mathrm{st}-\mathrm{NHSMA}_{2}\right)$ amphiphilic diblock copolymer solution in $\mathrm{CHCl}_{3} / \mathrm{CH}_{3} \mathrm{OH} 3 / 1 \mathrm{v} / \mathrm{v}$ solvent mixture was prepared. This polymer solution was electrosprayed at $20 \mathrm{kV}$ and at a flow rate of $0.005 \mathrm{~mL} \mathrm{~min}^{-1}$ onto an aluminium foil covered earthed collector plate at a working distance of $5 \mathrm{~cm}$ to produce microparticles. The obtained microparticles were imaged by scanning electron microscopy (SEM) using an eSEM-FEI Quanta FEGEnvironmental SEM Oxford ExACT instrument. The diameters of the particles were found to be between 2 and $8 \mu \mathrm{m}$. Using the same conditions, $0.36 \% \mathrm{w} / \mathrm{w}$ rhodamine $\mathrm{B}$ was added to the polymer solution prior to electrospraying to encapsulate the dye in the polymer microparticles.

\section{$\mathrm{PLA}_{114}-b-\mathrm{P}\left(\mathrm{MPC}_{17}-\right.$ st-NHSMA $)$ polymer microparticles - cysteine} conjugation

The cysteine (Cys) conjugation to the NHS-functionalized $\mathrm{PLA}_{114}-b-\mathrm{P}\left(\mathrm{MPC}_{17}\right.$-st-NHSMA $\left.{ }_{2}\right)$ diblock copolymer microparticles was conducted using the following procedure: $\mathrm{PLA}_{114}-b$-P(MPC ${ }_{17}-$ st-NHSMA $\left.{ }_{2}\right)$ diblock copolymer microparticles $(63.38 \mathrm{mg}, 0.0031 \mathrm{mmol})$ prepared by electrospraying were added to $2 \mathrm{~mL}$ of phosphate buffered saline (PBS) buffer in a vial equipped with a magnetic stirring bar. A mixture of cysteine $(1.69 \mathrm{mg}, 0.0139 \mathrm{mmol}, 2.25 \mathrm{eq}$. relative to NHS reactive groups) and (tris(2carboxyethyl)phosphine) (TCEP, $0.77 \mathrm{mg}, 0.0031 \mathrm{mmol}$ ) in $1 \mathrm{~mL}$ of PBS buffer was prepared and added to the vial containing the polymer. The vial was equipped with a stirring bar and was sealed with a rubber septum. The resulting solution was purged with nitrogen gas for $20 \mathrm{~min}$ and left to stir at room temperature for $12 \mathrm{~h}$. The reaction product was dialysed against water (MWCO 1kD, 8 times) in order to purify the microparticles. Samples were taken for Fourier-transform infrared spectroscopy (FTIR) analysis using an Agilent Technologies Cary $630 \mathrm{FTIR}$ spectrometer, ${ }^{1} \mathrm{H}$ NMR $\left(\mathrm{D}_{2} \mathrm{O}\right)$ analysis and fluorescence labelling with FITC.

\section{Thiol-functionalized polymer microparticles - FITC conjugation}

The reaction of cysteine-functionalized $\mathrm{PLA}_{114}-b-\mathrm{P}_{\left(\mathrm{MPC}_{17}-s t-\right.}$ Cys $\mathrm{MA}_{2}$ ) polymer microparticles with FITC was conducted as follows: A solution of FITC $(0.804 \mathrm{mg}, 0.002 \mathrm{mmol})$ in $2.0 \mathrm{~mL}$ of water was mixed with $2.0 \mathrm{~mL}$ of a $2.0 \mathrm{w} / \mathrm{v} \%$ aqueous dispersion of $\mathrm{PLA}_{114}-b-\mathrm{P}\left(\mathrm{MPC}_{17}-\right.$ st-CysMA $\left.\mathrm{MA}_{2}\right)$ microparticles in a vial equipped with a magnetic stirring bar and sealed with a rubber septum. The resulting mixture was stirred overnight at room temperature. Dialysis (MWCO 1kD, 8 times) against water was performed to remove any unreacted FITC. The microparticle solution was centrifuged through a $10000 \mathrm{MWCO}$ centrifugal concentrator (Eppendorf Centrifuge $5415 \mathrm{R}$ ) at $13200 \mathrm{rpm}$ to ensure the removal of unbound FITC. The resulting microparticle pellet was then collected and resuspended in water. The reaction was quantified in a 96-well plate using a Biotek Synergy 4 UV-Vis instrument, operating at a wavelength of $490 \mathrm{~nm}$ and using Gen5 software. Conjugated FITC was quantified via comparison to standards comprised of known concentrations of FITC whilst accounting for interference from the polymer. The fluorescein-labelled microparticles were imaged by Biotek cytation 5 imaging reader operating with an Olympus 20x PL FL objective (469/525 nm). This procedure was repeated using NHS-functionalized $\mathrm{PLA}_{114}-b-\mathrm{P}_{\left(\mathrm{MPC}_{17}-s t-\right.}$ $\mathrm{NHSMA}_{2}$ ) microparticles for comparison.

\section{Kinetic study of Rhodamine B release from PLA $114-b-P\left(M_{17} C_{17}-s t-\right.$ $\mathrm{NHSMA}_{2}$ ) polymer microparticles}

The fluorescent $\mathrm{PLA}_{114}-b-\mathrm{P}\left(\mathrm{MPC}_{17}-\right.$ st-NHSMA$\left.{ }_{2}\right)$ microparticles that were prepared by entrapping Rhodamine $B$ as a drug molecule surrogate were used in a kinetic release study. Rhodamine $B$ release from the microparticles due to the 
hydrolysis of PLA was investigated at $\mathrm{pH} 2$ representing the conditions of the stomach and also at $\mathrm{pH} 7.4$, mimicking physiological conditions. A $2 \mathrm{~mL}$ solution of Rhodamine B loaded microparticles prepared by electrospraying, with a polymer concentration of $15 \mathrm{mg} \mathrm{mL}^{-1}$ was added to a dialysis tubing (MWCO $1 \mathrm{kD}$ ). The tubing was placed in $0.1 \mathrm{M} \mathrm{HCl}-\mathrm{KCl}$ buffer solution at $\mathrm{pH} 2$ and in $0.1 \mathrm{M} \mathrm{PBS}$ at $\mathrm{pH} 7.4$ at $37{ }^{\circ} \mathrm{C}$ and the release kinetic study was performed for 89 days. $1 \mathrm{~mL}$ samples of the surrounding buffer were extracted at certain time points and replaced with $1 \mathrm{~mL}$ of fresh buffer. The release of the dye was assessed by UV-vis spectroscopy using Agilent Technologies Cary 60 UV-Vis spectrometer recording at wavelengths between 510 and $554 \mathrm{~nm}$.

\section{Results and discussion}

\section{Preparation of $\mathrm{PLA}_{114}-b-\mathrm{P}\left(\mathrm{MPC}_{17} \text {-st-NHSMA }\right)_{2}$ amphiphilic diblock copolymer}

To synthesize the PLA- $b$-P(MPC-st-NHSMA) amphiphilic block polymer, a hydroxyl functionalized dithiocarbonylthio agent (ROP-RAFT agent) that can initiate both ROP and RAFT polymerization $^{22}$ was used in an one pot, two-step synthetic procedure. The first step involved the ROP of LA in 1,2dichloroethane at $74{ }^{\circ} \mathrm{C}$ using DMAP as a catalyst. The reaction takes place due to the presence of a hydroxyl group at the end of the ROP-RAFT agent to produce a $\mathrm{PLA}_{114}$ hydrophobic homopolymer (Scheme 1a). This was followed by a second step that involved the RAFT polymerization of a monomer mixture of MPC with a small amount of NHSMA in ethanol at $78^{\circ} \mathrm{C}$ in the presence of ACVA initiator. The RAFT polymerization takes place due to the presence of a thiocarbonylthio group on the ROPRAFT agent, giving the $\mathrm{PLA}_{114}-b-\mathrm{P}\left(\mathrm{MPC}_{17}-s t-\mathrm{NHSMA}_{2}\right)$ amphiphilic diblock copolymer (Scheme $1 \mathrm{~b}$ ).

$A{ }^{1} \mathrm{H}$ NMR spectrum in $\mathrm{CDCl}_{3}$ (Fig. S1) was taken after ROP reaction for production of the PLA homopolymer. The spectrum showed a high LA monomer conversion of $95 \%$ after $45 \mathrm{~h}$, corresponding to a degree of polymerisation (DP) of 114 and a $\mathrm{MW}$ value of $16810 \mathrm{~g} \mathrm{~mol}^{-1}$ for the PLA block. The conversion was calculated by comparing the area under the ${ }^{1} \mathrm{H}$ NMR peak of the remaining unreacted LA monomer at $5.05 \mathrm{ppm}$ (methine proton) with that of the PLA polymer peak at $5.12 \mathrm{ppm}$. The $\mathrm{PLA}_{114}$ homopolymer was also characterised by SEC using $\mathrm{CHCl}_{3} / \mathrm{CH}_{3} \mathrm{OH} 3 / 1 \mathrm{v} / \mathrm{v}$ as eluent, poly(methyl methacrylate) (PMMA) as calibration standards and a refractive index detector (Fig. S2). A number average molecular weight $\left(M_{n}\right)$ value of 5 $350 \mathrm{~g} \mathrm{~mol}^{-1}$ and a dispersity $(\Theta)$ value of 1.16 were determined from the chromatogram. The ${ }^{1} \mathrm{H}$ NMR spectrum in a $\mathrm{CDCl}_{3} / \mathrm{CD}_{3} \mathrm{OD} 3 / 1 \mathrm{v} / \mathrm{v}$ solvent mixture (Fig. S3) of the crude amphiphilic block copolymer after the RAFT polymerization showed a high MPC monomer conversion of $93 \%$ after $24 \mathrm{~h}$, corresponding to a DP of 17 for the PMPC. The MPC monomer conversion was determined based on the resonance intensity of the unreacted MPC monomer at 5.42 and 5.94 ppm belonging to two methacrylic protons. The areas under these ${ }^{1} \mathrm{H}$ NMR peaks were compared to the combined polymer/monomer signals (Fig. S3, protons e, $\mathrm{f}, \mathrm{g}$ and $\mathrm{h}$ ) at the spectrum region between 3.42 and $4.11 \mathrm{ppm}$. The final reaction product was purified by dialysis, using a membrane with a MWCO of $1 \mathrm{kD}$, against acetone (4 times) followed by dialysis against methanol (4 times). The successful synthesis of the diblock copolymer was confirmed by ${ }^{1} \mathrm{H}$ NMR spectroscopy in $\mathrm{CDCl}_{3} / \mathrm{CD}_{3} \mathrm{OD} 3 / 1 \mathrm{v} / \mathrm{v}$ solvent mixture (Fig. S4) and SEC $\left(\mathrm{CHCl}_{3} / \mathrm{CH}_{3} \mathrm{OH} 3 / 1 \mathrm{v} / \mathrm{v}\right.$, Fig. S2). The presence of the $-\mathrm{CO}-\mathrm{CH}_{2}-\mathrm{CH}_{2}-\mathrm{CO}$ - peak at $2.72 \mathrm{ppm}$ in the ${ }^{1} \mathrm{H}$ NMR spectrum (Fig. S4) confirmed the incorporation of the NHSMA monomer on the hydrophilic PMPC polymer block. A monomodal molar mass distribution with a $€$ value of 1.43 and a $M_{\mathrm{n}}$ value of $6250 \mathrm{~g} \mathrm{~mol}^{-1}$ were determined by the SEC analysis of a sample of the purified diblock copolymer (Fig. S2). The $M_{\mathrm{n}}$ value by SEC was found to be lower than the MW value calculated by ${ }^{1} \mathrm{H}$ NMR (22 $200 \mathrm{~g} \mathrm{~mol}^{-1}$ ) spectroscopy. This was also the case for the $\mathrm{PLA}_{114}$ homopolymer. The difference in these values can be attributed to the lower refractive index increment $(d \mathrm{n} / d \mathrm{c})$ values of PLA in common SEC eluents compared to the ones of the PMMA calibration standards, resulting in inaccuracies in the SEC analysis of PLA-based block copolymers. For example, the $d \mathrm{n} / d \mathrm{c}$ value of PLA in $\mathrm{CH}_{3} \mathrm{Cl}$ is $0.024 \mathrm{~mL} \mathrm{~g}^{-1},{ }^{41}$ which is lower than that of PMMA in the same solvent $\left(0.0627 \mathrm{~mL} \mathrm{~g}^{-1}\right) .{ }^{42}$

\section{Electrospraying of $\mathrm{PLA}_{114}-b-\mathrm{P}\left(\mathrm{MPC}_{17}-\right.$ st-NHSMA $)$ amphiphilic diblock copolymer solution to produce microparticles}

For microparticle formation by electrospraying (Scheme 2a and 2b), a $\mathrm{PLA}_{114}-b-\mathrm{P}\left(\mathrm{MPC}_{17}-\mathrm{st}-\mathrm{NHSMA}_{2}\right)$ amphiphilic diblock copolymer solution in a $\mathrm{CHCl}_{3} / \mathrm{CH}_{3} \mathrm{OH} 3: 1 \mathrm{v} / \mathrm{v}$ solvent mixture was prepared at a concentration of $339 \mathrm{mg} \mathrm{mL}^{-1}$. The polymer solution was electrosprayed at $20 \mathrm{kV}$ and at a flow rate of 0.3 $\mathrm{mL} \mathrm{h} \mathrm{h}^{-1}$ onto an aluminium foil collector plate at a working distance of $5 \mathrm{~cm}$. SEM images showed the formation of microparticles by this method with diameters between 2 and 8
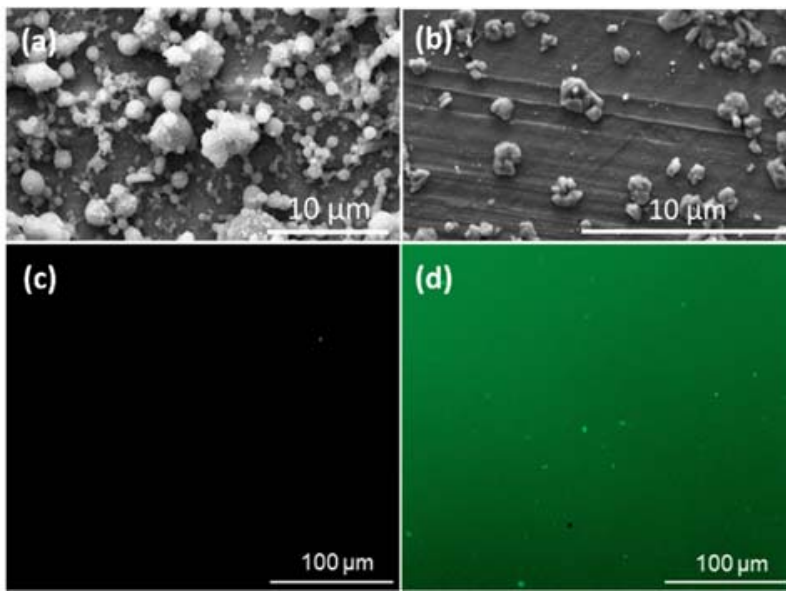

(d)

Fig. 1 SEM images of (a) NHS-functionalized $\mathrm{PLA}_{114}-b-\mathrm{P}\left(\mathrm{MPC}_{17}-\mathrm{st}-\mathrm{NHSMA}\right)$ polymer microparticles produced via electrospinning and (b) thiolfunctionalized $\mathrm{PLA}_{114}-b-\mathrm{P}\left(\mathrm{MPC}_{17}-\right.$ st-CysMA $\left.\mathrm{M}_{2}\right)$ polymer microparticles after cysteine attachment. Fluorescence microscopy images of (c) fluoresceinlabelled NHS-functionalized $\quad \mathrm{PLA}_{114}-\mathrm{P}\left(\mathrm{MPC}_{17}\right.$-st-NHSMA $\left.\mathrm{N}_{2}\right)$ polymer microparticles and (d) fluorescein-labelled thiol-functionalized $\mathrm{PLA}_{114}-b$ $\mathrm{P}\left(\mathrm{MPC}_{17}\right.$-st-CysMA $\left.\mathrm{A}_{2}\right)$ polymer microparticles. 
(⿻)

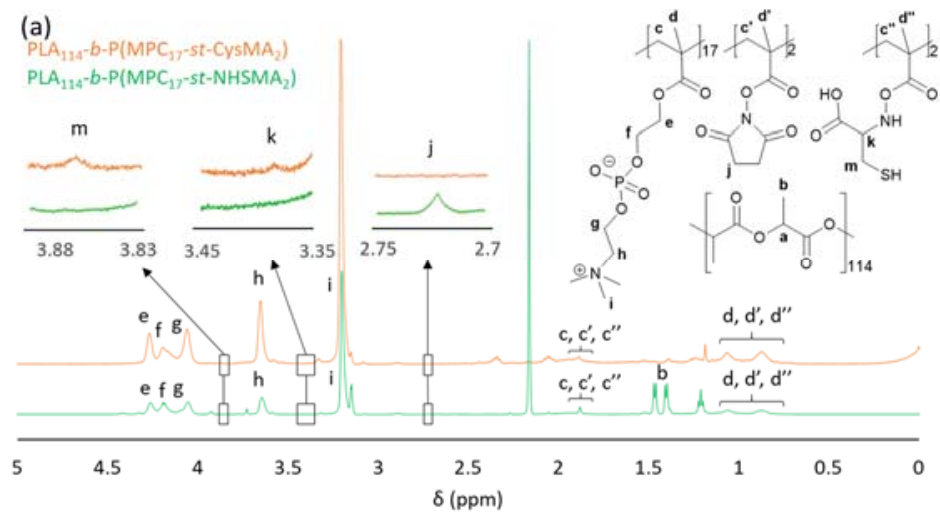

(b)

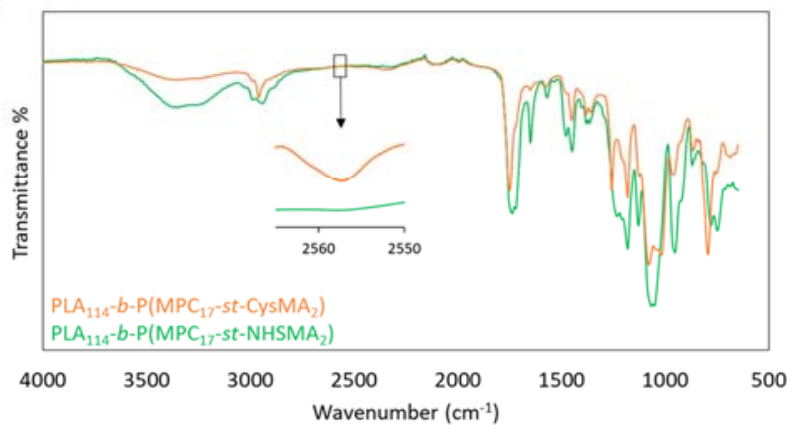

Fig. 2 (a) ${ }^{1} \mathrm{H}$ NMR $\left(\mathrm{D}_{2} \mathrm{O}\right)$ and (b) FTIR spectra of NHS-functionalized $\mathrm{PLA}_{114}-b$-P(MPC $\mathrm{MP}_{17}$-st-NHSMA ) amphiphilic diblock copolymer (green) and thiol-functionalized PLA $114-b$ $\mathrm{P}\left(\mathrm{MPC}_{17}\right.$-st-CysMA $)$ amphiphilic diblock copolymer microparticles (orange).

$\mu \mathrm{m}$ (Fig. 1a). Using the same electrospraying conditions, fluorescent microparticles with Rhodamine B encapsulated into their structures were prepared by addition of $0.36 \% \mathrm{w} / \mathrm{w}$ of the dye to the polymer solution prior to electrospraying (Scheme $2 d$ and e).

\section{Attachment of cysteine to $\mathrm{PLA}_{114}-b-\mathrm{P}\left(\mathrm{MPC}_{17}-\right.$ st-NHSMA 2$)$ polymer microparticles}

Attachment of cysteine $(1.7 \mathrm{mg})$ to $2.0 \mathrm{~mL}$ of a $2.0 \mathrm{w} / \mathrm{v} \%$ aqueous dispersion of the NHS-functionalized $\mathrm{PLA}_{114}-b$ $\mathrm{P}\left(\mathrm{MPC}_{17}\right.$-st-NHSMA $\left.\mathrm{N}_{2}\right)$ polymer microparticles was carried out in PBS buffer at $20^{\circ} \mathrm{C}$ in $16 \mathrm{~h}$ in the presence of $0.8 \mathrm{mg}$ of TCEP (Scheme 1c and Scheme 2c). The primary amine in the cysteine reacts with the NHS ester functional group on the microparticle surface forming a stable amide bond. With this reaction, the microparticle surface was decorated with free thiol groups (present in the cysteine molecule). Cysteine attachment was confirmed by ${ }^{1} \mathrm{H}$ NMR spectroscopy in deuterium oxide $\left(D_{2} \mathrm{O}\right)$ and FTIR spectroscopy (Fig. 2). In the $\mathrm{PLA}_{114}-b-\mathrm{P}\left(\mathrm{MPC}_{17}-s t-\right.$ $\mathrm{NHSMA}_{2}$ ) ${ }^{1} \mathrm{H}$ NMR spectrum (Fig. 2a), the peak at $2.72 \mathrm{ppm}$ in the $\mathrm{PLA}_{114}-b-\mathrm{P}\left(\mathrm{MPC}_{17}-\mathrm{st}-\mathrm{NHSMA}_{2}\right)$ spectrum represents the CO- $\mathrm{CH}_{2}-\mathrm{CH}_{2}-\mathrm{CO}$ - protons ${ }^{43}$ (j) of the NHSMA monomer, which they

are absent in the ${ }^{1} \mathrm{H}$ NMR spectrum of the cysteinefunctionalized $\quad \mathrm{PLA}_{114}-b-\mathrm{P}\left(\mathrm{MPC}_{17}-s t-\mathrm{CysMA}_{2}\right)$ polymer microparticles, since they are removed from the polymer during the cysteine attachment. The two new peaks appearing in the $\mathrm{PLA}_{114}-b-\mathrm{P}\left(\mathrm{MPC}_{17}-s t-\mathrm{CysMA}_{2}\right)$ polymer microparticle ${ }^{1} \mathrm{H} \mathrm{NMR}$ spectrum at $3.38 \mathrm{ppm}(\mathrm{k})$ and $3.87 \mathrm{ppm}(\mathrm{m})$ are due to the $\mathrm{SH}-$ $\mathrm{CH}_{2}-\mathrm{CH}-\mathrm{NH}_{2}-$ and $\mathrm{SH}-\mathrm{CH}_{2}-\mathrm{CH}-\mathrm{NH}_{2}$ protons of the cysteine molecule, respectively, confirming the successful cysteine attachment to the microparticles. The vibrational band at 2565 to $2550 \mathrm{~cm}^{-1}$ observed in the FTIR spectrum (Fig. 2b) of the $\mathrm{PLA}_{114}-b-\mathrm{P}\left(\mathrm{MPC}_{17}-s t-\mathrm{CysMA}_{2}\right)$ polymer microparticles is attributed to the presence of $\mathrm{S}-\mathrm{H}$ stretching vibration. ${ }^{44}$ As expected, this band is not present in the $\mathrm{PLA}_{114}-b-\mathrm{P}\left(\mathrm{MPC}_{17}-\mathrm{st}\right.$ $\mathrm{NHSMA}_{2}$ ) polymer microparticles prior to cysteine attachment, also confirming that the cysteine attachment reaction was successful. The thiol-functionalized $\mathrm{PLA}_{114}-b-\mathrm{P}\left(\mathrm{MPC}_{17}\right.$-st$\mathrm{CysMA}_{2}$ ) polymer microparticles were imaged by SEM (Fig. 1b).
The image obtained confirmed that the cysteine conjugation did not affect the microparticle morphology.

\section{Attachment of FITC to thiol functionalized polymer microparticles}

In order to check the reactivity of the free thiols on the cysteinefunctionalized $\quad \mathrm{PLA}_{114}-b-\mathrm{P}\left(\mathrm{MPC}_{17}-\right.$ st-Cys $\left.\mathrm{MA}_{2}\right)$ polymer microparticle surface, these were allowed to react with FITC to give a fluorescent tag. FITC $(0.8 \mathrm{mg})$ was allowed to react with a $2.0 \% \mathrm{w} / \mathrm{v}$ aqueous dispersion of $\mathrm{PLA}_{114}-b-\mathrm{P}\left(\mathrm{MPC}_{17}-\mathrm{st}-\mathrm{CysMA}_{2}\right)$ polymer microparticles for $16 \mathrm{~h}$ at $20^{\circ} \mathrm{C}$ under stirring (Scheme 1d). As a control, the same reaction was also performed using $\mathrm{PLA}_{114}-b-\mathrm{P}\left(\mathrm{MPC}_{17}-\mathrm{st}-\mathrm{NHSMA}_{2}\right)$ microparticles that do not contain any free thiols on their surface. The fluorescein treated polymer microparticles were imaged by fluorescence microscopy (Fig. 1c and 1d). A significantly higher number of fluorescein-labelled $\quad \mathrm{PLA}_{114}-b-\mathrm{P}\left(\mathrm{MPC}_{17}-\right.$ st-CysMA $\left.\mathrm{A}_{2}\right)$ microparticles were observed (Fig. 1d) compared to the $\mathrm{PLA}_{114^{-}}$ $b$-P( $\left(\mathrm{MPC}_{17}\right.$-st-NHSMA ${ }_{2}$ ) microparticles (Fig. 1c). The FITC conjugation was quantified by UV-Vis at $490 \mathrm{~nm}$ wavelength (Fig. S5). The quantity of FITC, in relative fluorescence units, attached to the $\mathrm{PLA}_{114}-b-\mathrm{P}\left(\mathrm{MPC}_{17}-\right.$ st-CysMA $\left.\mathrm{M}_{2}\right)$ microparticles was found to be four times higher than that of the FITC attached to the PLA $114-b-\mathrm{P}\left(\mathrm{MPC}_{17}-s t-\mathrm{NHSMA}_{2}\right)$ microparticles.

\section{Release kinetics of Rhodamine B from $\mathrm{PLA}_{114}-b-\mathrm{P}\left(\mathrm{MPC}_{17}-\mathrm{st}\right.$ - $\mathrm{NHSMA}_{2}$ ) polymer microparticles}

A dye release study of the electrosprayed Rhodamine $B$ containing $\left.\mathrm{PLA}_{114}-b-\mathrm{P}_{\left(\mathrm{MPC}_{17}-\text { st-NHSMA }\right.}\right)$ microparticles at $\mathrm{pH} 2$ (Scheme 2f) and $\mathrm{pH} 7.4$ (Scheme $2 \mathrm{~g}$ ) buffers at $37^{\circ} \mathrm{C}$ was performed. The $0.1 \mathrm{M} \mathrm{HCl}-\mathrm{KCl}$ buffer at $\mathrm{pH} 2$ was used to mimic the low $\mathrm{pH}$ environment of the stomach and the 0.1 M PBS buffer at $\mathrm{pH} 7.4$ (physiological $\mathrm{pH}$ ) was used as a control. For the release study, $2 \mathrm{~mL}$ of a $15 \mathrm{mg} \mathrm{mL}^{-1}$ Rhodamine $B$ loaded microparticle solution were placed in a dialysis tubing (MWCO of $1 \mathrm{kD}$ ) that was immersed in $58 \mathrm{~mL}$ of each buffer. At determined time points, $1 \mathrm{~mL}$ of the surrounding buffer solution was extracted and replaced with fresh buffer solution. The absorbance of the $1 \mathrm{~mL}$ samples was then measured by UV-vis at a wavelength range of $510-554 \mathrm{~nm}$. The release profiles for the Rhodamine B containing microparticles at $\mathrm{pH} 2$ and $\mathrm{pH} 7.4$, shown in Fig. 3 , demonstrate that the $\mathrm{PLA}_{114}-b-\mathrm{P}_{\left(\mathrm{MPC}_{17}-\text {-st- }\right.}$ 


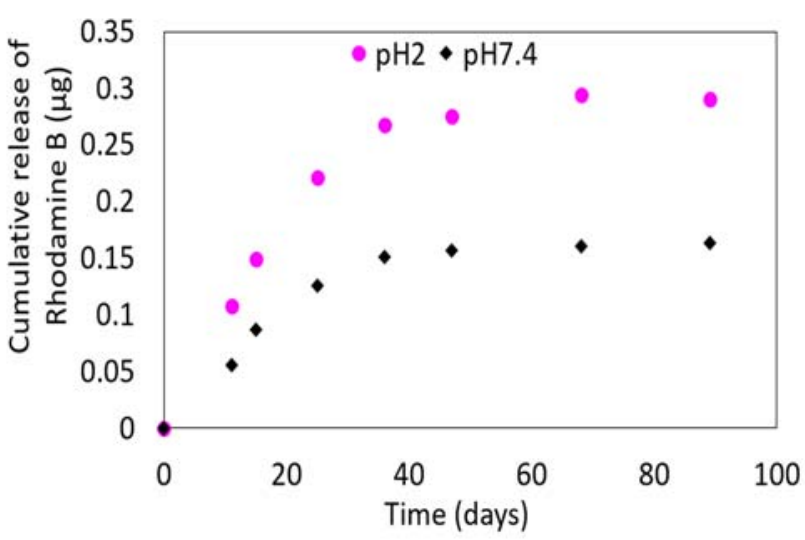

Fig. 3 Cumulative release profile of Rhodamine $B$ from $\mathrm{PLA}_{114}-b$ - $\mathrm{P}\left(\mathrm{MPC}_{17}-\mathrm{st}\right.$ $\mathrm{NHSMA}_{2}$ ) degradable microparticles in $\mathrm{pH} 2 \mathrm{HCl}-\mathrm{KCl}$ and $\mathrm{pH} 7.4 \mathrm{PBS}$ buffer solutions at $37^{\circ} \mathrm{C}$ over a period of 89 days.

$\mathrm{NHSMA}_{2}$ ) microparticles exhibit a controlled and gradual release over a period of 89 days without an initial burst. The polymer microparticles at $\mathrm{pH} 2$ release a higher amount of Rhodamine $\mathrm{B}$ than the ones at $\mathrm{pH} 7.4$, consistently over the studied 89-day period. This was attributed to degradation of the microparticle PLA cores at this lower $\mathrm{pH}$.

\section{Conclusions}

In summary, an NHS-functionalized $\mathrm{PLA}_{114}-b-\mathrm{P}\left(\mathrm{MPC}_{17}-\right.$ st$\mathrm{NHSMA}_{2}$ ) amphiphilic diblock copolymer was synthesized by sequential ROP and RAFT polymerization using a dual ROP-RAFT agent. A solution of this polymer was electrosprayed to produce NHS-functionalized degradable polymer microparticles. Successful cysteine attachment, providing the microparticles with thiol functionality, was confirmed by ${ }^{1} \mathrm{H}$ NMR spectroscopy, FTIR spectroscopy and fluorescence microscopy. Encapsulation and controlled release of Rhodamine $B$ was observed and quantified by UV-vis. In conclusion, the approach presented here, provides an excellent method for the production of mucoadhesive degradable microparticles for drug delivery applications at low $\mathrm{pH}$.

\section{Conflicts of interest}

The authors declare no competing financial interest.

\section{Acknowledgements}

The authors acknowledge the Engineering and Physical Sciences Research Council (EPSRC) (S3804ASA) for funding the Ph.D. studentship of M.F. Dr Peter Smyth and Prof Christopher J. Scott (Centre for Cancer Research \& Cell Biology, Queen's University Belfast) are thanked for their help with the fluorescence experiments.

\section{References}

1 A. K. Andrianov and L. G. Payne, Adv. Drug Deliv. Rev., 1998, 34,
155-170.

2 Y. Kawashima, T. Niwa, H. Takeuchi, T. Hino and Y. Itoh, J. Pharm. Sci., 1992, 81, 135-140.

3 A. Lamprecht and Y. Kawashima, J. Drug Deliv. Sci. Technol., 2006, 16, 25-34.

4 P. Rathee, M. Jain, A. Garg, A. Nanda and A. Hooda, J. Pharm. Res., 2011, 4, 1448-1453.

5 R. Thakor, G. Rajput, F. Majmudar, J. Patel and N. Rajgor, Syst. Rev. Pharm., 2010, 1, 70.

6 V. V. Khutoryanskiy, Macromol. Biosci., 2011, 11, 748-764.

7 G. P. Andrews, T. P. Laverty and D. S. Jones, Eur. J. Pharm. Biopharm., 2009, 71, 505-518.

8 J. M. Lü, X. Wang, C. Marin-Muller, H. Wang, P. H. Lin, Q. Yao and C. Chen, Expert Rev. Mol. Diagn., 2009, 9, 325-341.

9 H. Kranz and R. Bodmeier, Int. J. Pharm., 2007, 332, 107-114.

10 F. Qi, J. Wu, H. Li and G. Ma, Front. Chem. Sci. Eng., 2019, 13, 1427.

11 S. Freiberg and X. X. Zhu, Int. J. Pharm., 2004, 282, 1-18.

12 B. K. Lee, Y. Yun and K. Park, Adv. Drug Deliv. Rev., 2016, 107, 176-191.

13 F. Nederberg, E. F. Connor, M. Möller, T. Glauser and J. L. Hedrick, Angew. Chemie - Int. Ed., 2001, 40, 2712-2715.

14 E. F. Connor, G. W. Nyce, M. Myers, A. Möck and J. L. Hedrick, J. Am. Chem. Soc., 2002, 124, 914-915.

15 G. Moad, E. Rizzardo and S. H. Thang, in Australian Journal of Chemistry, 2012, 65, 985-1076.

16 J. Chiefari, Y. K. Chong, F. Ercole, J. Krstina, J. Jeffery, T. P. T. Le, R. T. A. Mayadunne, G. F. Meijs, C. L. Moad, G. Moad, E. Rizzardo and S. H. Thang, Macromolecules, 1998, 31, 5559-5562.

17 U. Capasso Palmiero, M. Sponchioni, N. Manfredini, M. Maraldi and D. Moscatelli, Polym. Chem., 2018, 9, 4084-4099.

18 J. Sun, S. Fransen, X. Yu and D. Kuckling, Polym. Chem., 2018, 9, 3287-3296.

19 Y. C. Yu, G. Li, H. U. Kang and J. H. Youk, Colloid Polym. Sci., 2012, 290, 1707-1712.

20 I. Yildirim, P. Sungur, A. C. Crecelius-Vitz, T. Yildirim, D. Kalden, S. Hoeppener, M. Westerhausen, C. Weber and U. S. Schubert, Polym. Chem., 2017, 8, 6086-6098.

21 H. Dong, Y. Zhu, Z. Li, J. Xu, J. Liu, S. Xu, H. Wang, Y. Gao and K. Guo, Macromolecules, 2017, 50, 9295-9306.

22 E. Themistou, G. Battaglia and S. P. Armes, Polym. Chem., 2014, 5, 1405-1417.

23 S. J. Shin, Y. C. Yu, J. D. Seo, S. J. Cho and J. H. Youk, J. Polym. Sci. Part A Polym. Chem., 2014, 52, 1607-1613.

24 H. U. Kang, Y. C. Yu, S. J. Shin and J. H. Youk, J. Polym. Sci. Part A Polym. Chem., 2013, 51, 774-779.

25 H. U. Kang, Y. C. Yu, S. J. Shin, J. Kim and J. H. Youk, Macromolecules, 2013, 46, 1291-1295.

26 Y. C. Yu, G. Li, J. Kim and J. H. Youk, Polymer (Guildf)., 2013, 54, 6119-6124.

27 A. G. O. De Freitas, S. G. Trindade, P. I. R. Muraro, V. Schmidt, A. J. Satti, M. A. Villar, A. E. Ciolino and C. Giacomelli, Macromol. Chem. Phys., 2013, 214, 2336-2344.

28 P. Viswanathan, E. Themistou, K. Ngamkham, G. C. Reilly, S. P. Armes and G. Battaglia, Biomacromolecules, 2015, 16, 66-75.

29 A. Bernkop-Schnürch, Adv. Drug Deliv. Rev., 2005, 57, 15691582. 
30 A. Štorha, E. A. Mun and V. V. Khutoryanskiy, RSC Adv., 2013, 3, 12275-12279.

31 R. Bodmeier and J. W. Mcginity, J. Microencapsul., 1987, 4, 279288.

32 M. Husmann, S. Schenderlein, M. Lück, H. Lindner and P. Kleinebudde, Int. J. Pharm., 2002, 242, 277-280.

33 J. A. Straub, D. E. Chickering, C. C. Church, B. Shah, T. Hanlon and H. Bernstein, J. Control. Release, 2005, 108, 21-32.

34 C. U. Yurteri, R. P. A. Hartman and J. C. M. Marijnissen, KONA Powder Part. J., 2010, 28, 91-115.

35 A. Jaworek and A. T. Sobczyk, J. Electrostat., 2008, 66, 197-219.

36 A. Jaworek, Powder Technol., 2007, 176, 18-35.

37 M. A. Elsawy, K. H. Kim, J. W. Park and A. Deep, Renew. Sustain. Energy Rev., 2017.

38 K. Ishihara, H. Oshida, Y. Endo, T. Ueda, A. Watanabe and N. Nakabayashi, J. Biomed. Mater. Res., 1992, 26, 1543-1552.

39 D. J. Irvine, A. M. Mayes and L. G. Griffith, Biomacromolecules, 2001, 2, 85-94.

40 J. Rosselgong, A. Blanazs, P. Chambon, M. Williams, M. Semsarilar, J. Madsen, G. Battaglia and S. P. Armes, ACS Macro Lett., 2012, 1, 1041-1045.

41 T. Malmgren, J. Mays and M. Pyda, J. Therm. Anal. Calorim., 2006, 83, 35-40.

42 R. Brown, Refractive Increment Data-Book, 2002, vol. 20.

43 M. Y. Bai, S. L. Tang, M. H. Chuang, T. Y. Wang and P. Da Hong, Front. Pharmacol., 2018, 9, 1025.

44 W. Zhao, B. Song, J. Tao, J. Zhang, M. Huang, C. Wang and M. Gou, J. Nanomater., 2016, 2016, 1-10. 